\title{
"Why We Deliver Elsewhere": Women's Preferred Places of Delivery and Their Effects
}

\author{
Perpetual Nancy Baidoo Kodom ${ }^{1, *}$, Michael Kodom², Kojo Senah ${ }^{3}$ \\ ${ }^{1}$ Sociology Department, University of Ghana, Ghana \\ ${ }^{2}$ Institute of Statistical Social and Economic Research (ISSER), University of Ghana, Ghana \\ ${ }^{3}$ Professor, Department of Sociology, University of Ghana, Ghana
}

Copyright $\bigcirc 2018$ by authors, all rights reserved. Authors agree that this article remains permanently open access under the terms of the Creative Commons Attribution License 4.0 International License

\begin{abstract}
Despite the crucial role hospital assisted delivery plays in reducing maternal and perinatal mortality and morbidity rates in Ghana, there continue to exit a gap between women who fully utilize antenatal care service but deliver outside the hospital. This study was conducted in Assin Fosu in the Central Region of Ghana, where maternal mortality rate is higher than the national average. It was to examine why women prefer to deliver outside the hospital. A qualitative approach was adopted to gather data through an in-depth-interview from 45 respondents. The results revealed that the use of TBAs and home delivery were preferred by some women despite the availability of hospitals because a number of them believed that institutional delivery was only aimed at women who experience obstetric complications. Attitude of public health workers and financial constraints were the two major factors that prevented women from accessing and using institutional deliveries.
\end{abstract}

Keywords Traditional Birth Attendant, Antenatal Care, Supervised and Unsupervised Delivery, Maternal Mortality

\section{Introduction}

Globally, it has been estimated that approximately 1000 women die each day from pregnancy-related complications. 99 percent of such deaths occur in developing countries and more than 50 percent in sub-Saharan Africa [1]. Though the recent worldwide statistics show a significant decline in maternal and child mortality, the rates are still high among developing countries, especially in sub-Saharan Africa. The lifetime risk of maternal deaths according to the World Health Organization (WHO) in sub-Saharan Africa is estimated at 1 in 39 as compared to 1 in 290 in South-Eastern Asia and 1 in 3800 in developed countries [2]. Ghana has persistently unacceptable high maternal mortality ratio of 350 to 100,000 live births as at
2012 [3]. Therefore, the Millennium Development Goals five (MDGs 5) sought to improve maternal health and this has currently been reinforced by the Sustainable Development Goal three (SDG 3) which also seeks to ensure good health and wellbeing.

Among the causes of maternal mortality, unsupervised delivery has been known to be one of the leading indicators. There is, therefore, the emerging consensus in literature that a greater proportion of all these deaths can be prevented if deliveries are overseen by skilled midwives. Research has shown that some of the best strategies to improving perinatal outcome of both mothers and their babies is the assistance by healthcare professionals during childbirth who have the expertise to deal with complications in childbirth as well as the existence of effective postnatal healthcare system especially within the first 24 hours of delivery $[4,5]$. Hence, this makes the place of delivery essential to maternal mortality [6].

Generally, women have a different preference for their places of delivery. Whiles majority prefer to deliver in the hospital, others prefer non-facility delivery; a rational choice decision usually made out of existing or perceived socioeconomic constraints [7]. Sub-Saharan Africa records some of the lowest facility delivery rates in the world. The results of a study across 28 countries in the sub-Saharan African region have shown that only as low as $47 \%$ women deliver in a health facility [8]. It was also observed that whiles some women access antenatal care (ANC), they actually do not go back to deliver in the healthcare facility. This was also found in an earlier study by Telfer, Rowley and Walvaren [9] in Gambia that the proportion of women who utilize ANC and delivered at the hospital was as low as $30 \%$.

In Ghana, there is also a gap between women who utilize ANC but deliver elsewhere. 'Elsewhere' in this paper represents women who do not deliver at supervised places. The Figure below presents the trends in ANC and place of delivery in Ghana according to the Ghana Demographic and Health Surveys conducted from 1988 to 2008 and the 2011 Multiple Indicator Cluster Survey. 


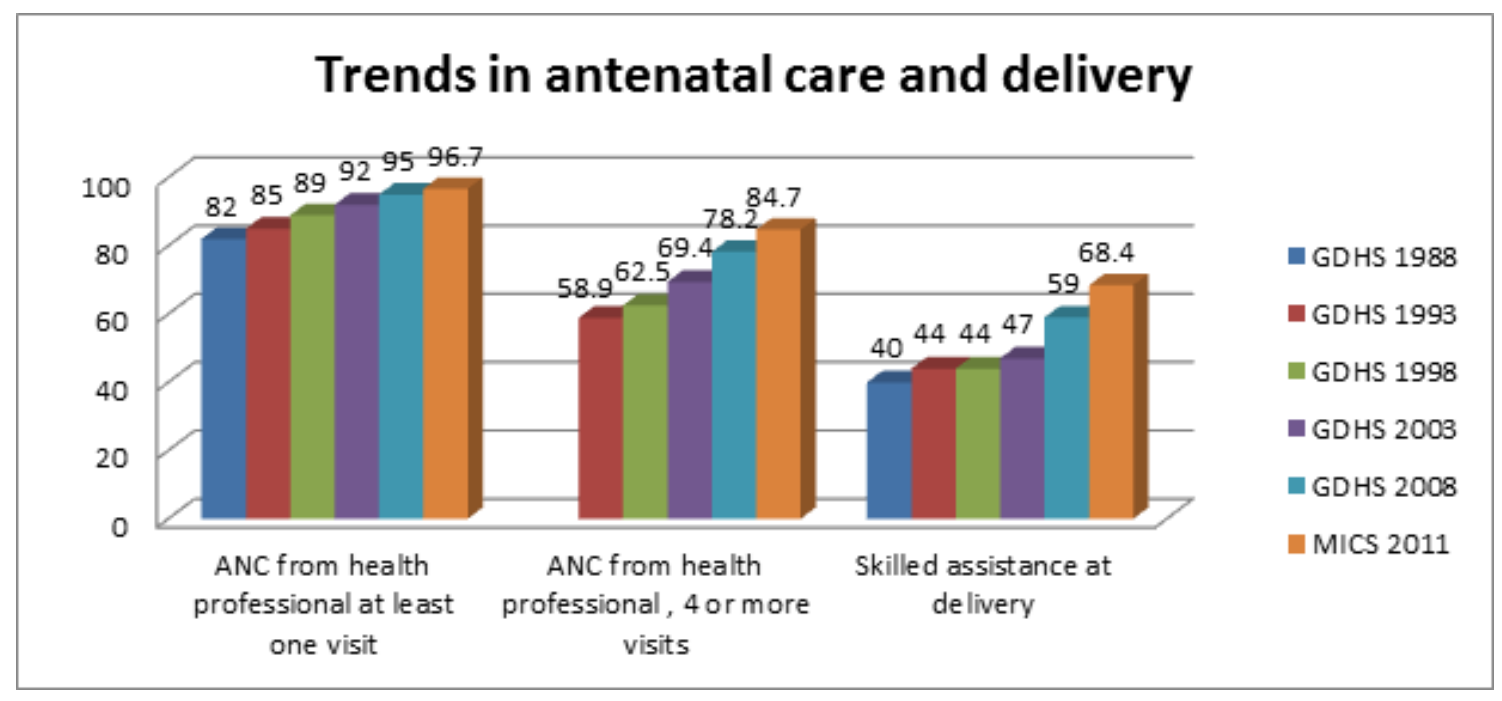

Source: Ghana Health Service [10]

Figure 1. Trends in Antenatal Care and Delivery

In the chart above, women who attended ANC at least once increased considerably from 82 percent to approximately 97 percent between 1988 and 2011 respectively. Though women who attended ANC at least four times also increased from 59 percent to 85 percent within the same period, there was a reduction in the number between the two groups (one-time visit and four or more visits). Interestingly, the number of women who delivered finally in health facilities reduced drastically. In an effort to encourage the attendance to ANC and supervised delivery, Ghana in September 2003 introduced the fee-free delivery exemption policy for users of maternity services from paying fees [11]. Even though it brought about a slight improvement, the problem still persists.

Taking 2011 into consideration, the data showed that as many as 97 percent of women attended ANC at least once and 85 percent also attended at least 4 times, but only 68 percent registrants actually delivered in a health facility. The question then is where did the remaining women ( 29 or 17 percent) go? Although the number of attendance has been used to describe the problem, the interest of this paper is in the gap that has been created because the percentage of registrants has consistently been higher than the percentage of deliveries. With this description of the gap, this paper answers three key questions; (1) Where do women prefer to deliver? (2) What factors influence preferred places of delivery? and (3) What are the effects of the place of delivery on the mother and baby's health?

The underlying theory of this study is the rational choice theory. Sociologists and other scholars within the social science disciplines have used this theory to explain the character of people towards a course of action. They explain that the actions of people are fundamentally guided by a cost-benefit analysis of the action before undertaking it [7]. The theory was first pioneered by sociologist George Homans [12] and over the period of time, many economic and health theories have adopted the theory to explain people behavior towards the production and consumption of goods and services. Basically, the theory argues that the decision of people to take a course of action, either to engage in an activity or refrain from an activity are usually guided by the individual's assessment of his own goals and preferences after carefully evaluating the outcome of the actions. Usually, this rational decision is undertaken after carefully evaluating the outcome of all existing alternatives. The final choice is presumed to give the individual the maximum satisfaction, usually in the midst of resources constraints and existing culture within a particular space and time. Conceptualizing the theory in the context of this study, individuals make deliberate and calculative efforts to make choices that will be beneficial to them. This means that the choice a woman makes to deliver in a hospital or with a TBA is rational. She considers the benefits, challenges, gains, and disadvantages with each choice before arriving at a final decision.

\section{Study Area}

According to the 2010 Population and Housing Census, Central Region, like other three regions (Northern, Upper West and Upper East) recorded maternal mortality figures higher than the national average. The maternal mortality for Central Region is 520 per 100,000 live births as compared to the national average of approximately 485 . Out of the 17 districts in the region, Assin North recorded the second highest in maternal mortality in 2012. Since Assin North municipal is a large district comprising 21 communities, the capital Assin Fosu was used in this study. It is mainly a farming and trading community with a population of 20,541 [13].

The population is largely youthful. About 40 percent of the population, aged 12 years and older in Assin North have never married while about the same percentage is 
currently married. 11 percent of the remaining group is widowed with the others either separated or in an informal or consensual union. The proportion of females who are illiterate is higher than that of males. The number of people with only basic level education is very high. The proportion currently pursuing tertiary programs are males $(1.7 \%)$ and females $(1.1 \%)$.

The Francis Xavier General Hospital is the biggest (mission) hospital in Assin Fosu. It provides a wide range of health care services and it is the nearest referral hospital that serves the Assin North Municipality and its environs. With the introduction of the National Health Insurance Scheme (NHIS) and the broad range of services it provides, most of the local people prefer to seek medical care directly at this hospital. There are also five (5) registered private clinics, polyclinics and maternity homes well spread in the Assin Fosu community which supplements the efforts of the only public health facility available.

\section{Methods}

Within the scope of this study, the researcher adopted a qualitative method in data collection. The use of this method enabled an in-depth understanding of the phenomenon as it allowed the researcher to ask follow-up questions to clarify issues [14]. Respondents were sampled based on convenience and their availability and they were interviewed at their workplaces, mainly the market or in a retail shop.

Different groups of participants were selected as part of our study population. The sample comprised of both women and men (who are involved in the decision-making process about delivery), healthcare providers (i.e. health professionals, including midwives and nurses, private clinic operators) and Traditional Birth Attendants (TBAs).

Using the saturation method as a guide, a total of 31 women (i.e. all women in their reproductive ages including; the pregnant, young and old), 4 TBAs, 2 nurses, 1 midwife, 6 men and 1 church priestess were interviewed. This means that the total number of people used for the study was 45 .

The responses from the interviews were transcribed, coded and themes were generated from the codes that were developed. Thus, based on the trends of responses that were observed, the results were grouped under thematic areas. Therefore, the main method used for the presentation of the interview data was thematic analysis.

\section{Results and Discussion}

\section{Preferred Places of Delivery}

The question of where women intend to deliver or actually delivered seemed to get most respondents thinking and recollecting old memories. Responses derived can be grouped into three categories: delivery at a health facility, at home with TBAs and at prayer camps. Out of the thirty-one women interviewed, twenty-four preferred to deliver at health facilities, six preferred home deliveries and only one preferred delivery at a prayer camp. The preference of majority of the women to deliver in a healthcare facility is consistent with studies that have been conducted in countries such as Democratic Republic of Congo [15], Kenya [16], Nepal [17], Tanzania [18] and even an earlier study across the three ecological zones of Ghana [19]. In all these studies, majority of the women in the sample either delivered or preferred to deliver at a healthcare institution. It was found that even though each woman had her preference for where to deliver, they all started antenatal care at a hospital facility. This was mainly to check for obstetric complications. Most of them believed that once they do not have any complications such as pregnancy-induced hypertensions, anaemia, ectopy and others, they could safely deliver their babies in the church or at home. In their study, Amooti-Kaguna and Nuwaha [20] found that women's high preference for institutional delivery is sometimes influenced by abnormal pregnancies which need professional healthcare assistance compared to normal pregnancies. This shows the decision (rational choice decision) of a woman to deliver at a particular place is a function of her previous experience and perceived delivery outcomes, which are both subject to existing or perceived socioeconomic constraints.

\section{Delivery at another Health Facility}

From figure 1, a gap was observed between ANC registrants and deliveries. This gap does not necessarily mean the women who did not go back to the health facilities where they attended ANC had an unsupervised delivery. Thus, some women delivered at health facilities they did not attend ANC. Health facilities come in the form of hospitals, maternity homes, clinics or polyclinics. Why these women actually delivered in another health facility is explained by unanticipated outcomes. These include complications, emergency or sudden births and relocation.

Some had complications along the line and they had to be transferred to a higher-level hospital for assistance. Most of these women had to go through cesarean sections (CS). Others also had sudden births and might have had to be rushed to the nearest health facility. Most of the women who were delivering for the first time also had to relocate to their mother's places because they had no or little experience with childcare. One said;

With my first child, I had to travel to my mum in Kumasi because I was inexperienced. I really wished to deliver at St. Francis because that is where I have had my ANC but I didn't know anything about babies. I didn't even know how to change baby's diapers let alone bathe him. On the other hand, I couldn't have let my mum come to 
Assin Fosu because my husband and I live in just a single room here. So, I had to go (female, Trader).

On another hand, although some attended ANC at a public hospital, it is actually a private hospital they delivered or intended to deliver. This was mainly due to the perceived bad attitude of nurses in public hospitals. A woman lamented:

One nurse embarrassed me so much when I was delivering my very first child. I didn't know I had to shave before labor. During my pregnancy, because of my big stomach, it was very difficult to bend and shave so I had not shaved for months. When the nurse saw my pubic area, she quickly ran out screaming and calling all the other nurses to come and see. I felt so bad and even started crying. Since then, I delivered the rest of my two children at a private hospital. I don't know why nurses have to be so rude. And the worse of it is it happens in almost all public hospitals! So, if you have the means just deliver at a private hospital to avoid being insulted and tortured (female, secretary).

Most women who have assessed these factors and are 'well-to-do' preferred to deliver at private hospitals where they can enjoy quality health care compared to delivering at government hospitals, with TBAs, or prayer camps. This is also evident in the work of Mrisho et al [21]. According to them, quality of services was perceived to play a major role in the choice of place of delivery. For example, some women decided to go to private health facilities, where they had to pay, despite government health facilities with free delivery services due to the quality of care given them at the private health facilities.

\section{Domiciliary Delivery}

The interest of the paper lies in women who had an unsupervised delivery although they went through ANC in a health facility. In 1997, WHO and many safe motherhood advocates turned their attention from the training of TBAs to skilled birth attendants for all and calling for new roles for TBAs rather than conducting deliveries. It was advocated that all pregnant women must go through a supervised delivery. Also in 2010, the Ministry of Health released a joint communiqué with WHO to ban TBAs from conducting deliveries in communities that already had health facilities.

Therefore, it was interesting to investigate why some women still prefer to deliver elsewhere. From the interaction with the women, none of them knew about this policy from the ministry. Although the TBAs had knowledge of the policy, they also did not stop the women from coming to patronize their services. The services of TBAs was initiated by the WHO in 1987 in Nairobi, Kenya, through the launching of the Safe Motherhood Initiative, aimed at ensuring women have a safe pregnancy and childbirth $[22,23]$. Despite the low literacy among TBAs, studies have shown that they play a crucial role in the maternal health of women especially in developing countries like Ghana. It had been reported that around 30\% of neonatal mortality could be reduced by implementing skilled birth care services [24]. In Ghana, the first practical step toward the use of TBAs by the health system was on the Danfa project in the 1970s. As part of extending public health care to rural communities as a result of the 1978 Alma-Ata Declaration, the training of TBAs assumed a national character. This earlier TBA training programme was to improve perinatal care.

The stories behind delivering at home were much expressed with passion by the respondents. All of them seemed to despise health facility delivery with much enthusiasm. They expressed the considerable delay in hospital delivery as a major reason as also expressed by Senah [25], who identified six delays in hospital delivery. They include; delay in arriving at the facility (transportation challenges), delay within the facility (no competent personnel, inadequate equipment), delay in producing requirements (such as detol, diapers, gloves, cot sheets etc.), delay in recognizing the problem, delay in taking a decision (especially by nurses) and delay in post-partum care.

Some of the reasons the respondents gave for their choice in domiciliary delivery also revolve around these delays. They gave reasons such as; TBAs being patient, TBAs effective traditional assistance to aid delivery, domiciliary delivery being a family tradition, perception about the bad attitude of nurses towards women in labor, domiciliary delivery being less expensive, and high knowledge of traditional medicine, among others. Most of the women therefore preferred not to deliver in the hospital but elsewhere because they considered the hospitals as inappropriate childbirth environment. This can be inferred from some of the responses they gave such as:

I went to ANC to check if everything was OK. But its home I preferred to deliver because that is the family tradition. The TBAs are equally good and can handle all complications. In the case of my last born, the after birth (placenta) did not come out after the delivery. So, the TBA immediately peeled some plantains and pushed it into my mouth down to my throat. When I tried to vomit, all the afterbirth dropped within some few seconds. The hospital could not have done this (woman, farmer).

Another said:

I prefer delivering at home because when you are in labor, even if it's a day, the TBAs spends the whole day with you. They have a lot of time for people. They will sit by you to wipe your sweat. But at the hospital, they will keep moving up and down and you will lie there dying and you don't seem to know what else they are employed to do! My advice is, if you don't have a friend at the hospital, don't deliver there (woman, trader)! 
A man also commented:

Whenever my wife goes into labor, the first thing I do is call a TBA. If she (TBA) believes that the labor can be managed at home, we deliver at home. We can't afford all those items on the list the hospital expects. The most annoying is if some of the items are unused they won't return them to the woman. We have confidence in the TBAs. They don't demand those lists either. (male, trader).

Another added:

I hate nurses. I hear stories where they are so cruel to the patients that some die when nurses could have really saved them. A friend told me that when she was in labor, her husband had to actually bribe all the nurses and the midwives before they paid attention to his wife. The women in labor were many and what is so special about you in particular for them to give you a lot of care? Unless they are bribed! They actually call it 'tip' but I know its bribery. I prefer home delivery (female, unemployed).

A female student also added that:

I was a teenager when I got pregnant so I felt shy to go to the hospital. My mum insisted I went but I couldn't imagine myself sitting with grown-ups in a queue and some staring at me with inquisitive eyes or even the bold ones asking me questions. So, I never went and when I was due to deliver too, I went to a TBA.

These findings support the tenets of the rational choice theory and findings from the work of Amooti-Kaguna and Nuwah [20]. Amooti-Kaguna and Nuwah [20] found in their work that women who preferred delivery with TBAs gave the most prominent reason for their choice as the potency of traditional medicine/herbs; which is said to have various roles such as making the fetus to grow well, cleansing the birth canal, treating and preventing some sexually transmitted diseases, and preventing and treating abnormal vaginal discharges.

Also, according to Titaley et al. [26], the flexibility of the payment method for TBAs was more convenient for most women. They again confirmed that TBAs were more mature, patient and caring as compared to nurses and midwives. Nogueira [27] and Jewkes et al. [28] also reported in their study that part of the problem lies in violence committed by health workers, which affects health-service access, compliance, quality, and effectiveness. The abuse of health workers, especially nurses, reflects in neglect, verbal and physical abuse. Expectant mothers were also said to have been abused if they had never attended ANC or if they have had many children already [20].

\section{Superstitious beliefs about Pregnancy}

Another contributing research finding from this paper that was not so evident in the literature is the superstitious beliefs of the people. Each culture has its own beliefs regarding pregnancy. Some of these beliefs cut across sicknesses, labor, appearance and eating habits. For instance, a pregnant woman should not eat pawpaw, snails or eggs. The belief is that if she eats snails and eggs, she is chewing her unborn baby and if she eats pawpaw, the baby's head will be too soft. Some of the beliefs about her appearance are, she must not tie clothes around her neck otherwise the baby will tie its umbilical cord around itself and that will make it very difficult to push it out.

She must not retarch (perm) her hair because if she does, she is cooking up the baby. She must not use a comb to split her hair when braiding or else the baby will be born with cuts all around its body. She must not help someone to put down a load without a 'protection' or charm on her (the pregnant woman) otherwise if the other woman she is helping has a 'bad eye' (witch), she can kill the foetus. Lastly, the pregnant woman must not eat outside her house or she can be given 'asram' from someone with a 'bad eye'. 'Asram' is the shrinking of the baby so that the baby delivered is as little as a lizard. The forehead turns green and more often they die within a week after delivery.

Even though these beliefs might affect or restrict the pregnant woman in one way or the other especially with the beliefs concerning the foods, the superstitions that really affected their place of delivery are the ones with regard to exposure of the woman in labor. Exposure can happen in two instances.

In the first instance, the body of the woman in labor must not be exposed otherwise she can be given the 'asram'. However, as a result of the excruciating pains, some women remove their clothes in a quest to seek some relief hence, exposing their bodies in the presence of both staff and patients who might have a 'bad eye'. On the other hand, the midwives come in once in a while to insert their fingers into the parturient's vagina as a way of checking the progress of dilating and by so doing exposing the woman's nakedness the more. Therefore, in order to evade all these and the risk of being given 'asram', she might opt to deliver alone at home with just a TBA.

In the second instance, the woman in labor must not be seen or heard by people. For example, one elderly woman said;

When you are in labor, people shouldn't hear you are in the hospital still waiting to deliver. Don't go too early to attract eyes. If people hear you have gone to the hospital for days to deliver, a witch can just remove her slippers and step on the ground barefooted. If they do that, you can never deliver. All they should hear is you have delivered. Then, it will be too late for them to do anything to you (elder woman, farmer).

This means that labor should be in secret and in a solitary place that does not call for attention. Hence, this is the reason for the domiciliary delivery. Various studies have 
reported barriers embedded in the beliefs and traditions of communities, the perception that health professionals do not pay sufficient attention to traditional norms of the society $[29,30,31]$. Ishikawa et al. [32] indicated that following traditional practices can also affect women's preferred place of delivery. That is, where the women in a family usually delivered is another strong social barrier to delivering in a health facility. West Africa has been identified by the $\mathrm{UN}$ as where superstitions run rampant, as the old practices of witchcraft, voodoo, juju, and marabou, brought about through old traditions and culture and the practicing native spiritual mediums of the area [33].

\section{Delivery at Prayer Camps}

Even though traditional practices attract Ghanaian women because of their time-tested methods, others chose to turn to their religion when it comes to having babies. And, indeed, since religion is so integrated into every aspect of life, why would childbearing be excluded [34]. None of the men interviewed wanted their wives to deliver at prayer camps. Of the respondents who preferred delivery at prayer camps (only one woman and the church priestess) gave mainly biblical reasons for this choice. They expressed the gratification for prayers offered them persistently till labor was over. They believe that childbirth was instituted by God and hence, delivery should be done in the house of God.

She gave her reason as:

Labour is a matter of life and death. At the prayer camp, if you are in labor, that day's service is for just you. You have the entire congregation supporting you in prayers. You will hear all of them praying outside the tent. This inspires, and energizes you, for you know you have heavens support. It takes away all fear (trader).

This, as well as the overall findings of this study concerning women's preferred place of delivery (healthcare facility, at home or prayer camp) shows that individuals make a deliberate and calculative choice just as the rational choice theory postulates.

\section{Effects of the Places of Delivery on the Health of Mother and Baby}

Interestingly, authorities in delivery (i.e. midwives, TBAs and the prayer camp priestess) gave opposing opinions about the effect of the place of delivery on the health of the mother and baby. Each of them claimed their facility was the best and condemned the other.

From the perspective of the TBA, delivering at their end had very little negative consequences on both the mother and the baby because it is less scary for the women as compared to the hospitals. They explained that some women are naturally afraid of hospitals because of the nature of the machines and equipment they use on the women. Others also complain of the smell that is in every hospital which makes them feel sicker and the worst part is seeing the next person die (before, during or after labor), which scares them and make them feel they can also die.

In the view of the TBAs too, the place a woman delivers can result in death. They believe home delivery has fewer effects on the mother because the women are pampered, it's less scary (because there are no huge machines) and it is more affordable. All of them indicated that not even a single woman or baby has died in their hands for the number of years they have worked as TBAs. They again added that they charge very little and sometimes, nothing at all for assisting a woman's delivery. They all admitted that their work is more of a missionary job than a business. Some of their responses are as follows. One TBA said;

Midwives and nurses don't have time for patients due to the large number of patients they receive every day. They even shout at women in labor but we pamper them. Should you go to the hospital to deliver at a time, and they check the expected time to deliver and you still have not delivered, they take you straight to the theatre and cut you open. But for us, assuming you come at 6 am and you are expected to give birth even at $4 \mathrm{pm}$ we have time for only you to wipe your sweat and tears. If the woman is still strong, we even walk around with her chatting until she is due to deliver. The hospital also has a lot of machines that even scare the women. With hospital delivery too, they don't mind seeing you die if you can't afford the cost and the list but we, on the other hand, do not demand any list or money. (female, TBA).

To the nurses and midwives, childbirth is a matter of life and death and hence should be handled by experts who have acquired professional training. According to them, the place of delivery is very vital to the survival of both the mother and baby. Some of the effects associated with the places of delivery are; ability to handle unexpected complications and perform cesarean sections. They explained that in cases where the mother has complications such as pregnancy-induced hypertension (PIH), hermorrage, ectopy, anaemia, sepsis, obstructed labor, breech presentation, the doctors can easily help by giving blood, drips or perform cesarean sections to save the mother and baby or at worst one of them.

In addition to the above complications for which a woman should deliver at the health center, the private hospital nurse also stressed that the woman should deliver at a place where good professional care is assured. At the private hospitals, they are given professional treatment and special care that make patients comfortable and content. Mrisho et al. [21] also confirmed that most women wish to deliver in private hospitals because the personnel at these hospitals are perceived to be very caring even though their services are expensive. They added that most women preferred the presence of their husbands or other close 
relatives during delivery, which private health facilities allow. Therefore, pregnant women who could as well afford the services of the private hospital should patronize it. These reasons support the view of some of the respondents in this study as evidenced by this statement from a retired midwife:

The hospital is the best. There are so many complications in pregnancy and childbirth like pregnancy-induced hypertension, sepsis, ectopy, obstructed labor, haemorrhage, anaemia, some even have STDs and in each case, they should be attended to in delivery especially. But the TBAs cannot determine these complications. If they see anything odd they will inject the patient using bulb syringes with herbs or insert some concoctions. More often, they give the same herb medication to different health cases. Finally, when they realize they cannot handle the situation, they push them to the hospital and by the time they get to us, we can do little or nothing about it. Then they die in our hands but the TBAs killed them! (female, retired midwife).

On the part of the church priestess, delivery should be supported by the presence of God. She believed birth was instituted by God and hence has no negative effect when done in the 'house of God'.

The results indicate that each of these 'delivery attendants' have in-depth knowledge and experience in their area of work. Each of them expressed the need for patients or women to patronize their services instead of the other. On the side of the respondents, while some of the respondents believed that the quality of services in terms of care and support received from nurses and midwives contributed to higher chances of survival, others also placed much significance on their ability to evade death due to the hospital's machines.

Therefore, the mother-to-be or patient must assess the pros and cons of each of these services and decide which one is best for her. A key strategy to reducing maternal deaths is the 'health-center intrapartum care strategy', where qualified skilled workers manage labor, effectively manage complications and are supported with effective referral systems for specialized care when needed [35]. It is for the safety of the mother and the baby that the country has banned the activities of the TBAs. Three of the TBAs who were interviewed and aware of the policy on the ban of their activities did not want to comment on it. The fourth person who commented briefly said they could not stop the women from coming to their end because the women could not afford the cost of a hospital delivery.

One finding from this paper that was contrary to the literature was proximity. Although proximity to health care facilities is an underlying issue for selecting delivery health care services, as also shown in previous literature [17-21, 36, 37], it did not seem to be the case in Assin Fosu. The Francis Xavier hospital, which most of the indigenes sought medical assistance was located right in the center of the town. In as much as there were many bad roads, they have a good road network that made transportation relatively easier as compared to other areas in the literature.

Another finding that was contrary to what has been discussed in literature is the role of men in the decision of the place of delivery. According to Amooti-Kaguna and Nuwaha [20] and Mrisho et al [21], the women admitted that the decision of place of delivery mostly depended on the husband. They continually quoted that the husband was 'the money maker'. Others who were also mentioned included the mother, mothers-in-law, aunt, sisters or counsel from TBAs and sometimes from health workers were also mentioned as influencing the choice of place delivery. Surprisingly, only one man confirmed that he takes the decision on the place of delivery. Most of the men interviewed asserted that they gave their wives the privilege to take that decision to compensate for the pain they go through. Almost all the women also reinforced that their husbands allow them to make the decisions on their preferred place of delivery.

\section{Conclusion and Recommendations}

Maternal mortality is disturbing in the lives of women. However, it is possible to reduce and even prevent it if the place of delivery is given an important look. Delivery at home cannot be branded as harmful even though it may have some major health implications for the mother and baby when there are complications. Just as this study supports the rational choice theory, that people make a conscious decision with each choice they make, many women will still deliver at home given the reasons they have elaborated. This makes it impossible to eliminate the services of TBAs and hence the policy to ban their operation should be reviewed. TBAs must be trained and equipped with instruments to meet formal and hygienic standards of delivery in order to save more lives. Experiences from other countries indicate that skilled attendants can be better promoted in a system that integrates traditional with the modern health system [26].

The study recommends that the Ministry of Health and the Ghana Health Service should eradicate abuse perpetrated by health-care workers against patients. Health workers need periodic training especially in the areas of communication with patients that includes mutual agreement and decisions on treatments, and recognition that they are ultimately responsible for the lives of their patients. Information, education and communication interventions targeting behavior change should address the various negative socio-cultural beliefs that people hold about pregnancies which have negative consequences on the wellbeing of mothers and the child. Policymakers should also take note that policies can be made but if they are not in line with the community belief systems, it will be difficult for them to yield their expected outcomes. 
Future studies should also explore for important motivation factors that can help improve communication between traditional birth attendants and the formal health system. Again, future research should employ a mixed method approach to complement the weakness of the qualitative approach.

\section{REFERENCES}

[1] World Health Organization. World Health Statistics, WHO, Geneva, 2008.

[2] World Health Organization. New UN Report: Maternal deaths nearly halved in 20 years: Trends in maternal mortality: 1990 to 2010, United Nations, New York, 2012. Online Available at

http://www.who.int/pmnch/media/news/2012/20120516_un fpa_report/en/

[3] Ministry of Health. Annual report of Ministry of Health, MOH, Accra, Ghana, 2012.

[4] A. A. Adegoke, N. van den Broek. Skilled birth attendance-lessons learnt, BJOG. Vol.116, 33-40, 2009.

[5] V. Filippi, C. Ronsmans, O. M. R. Campbell, W. J. Graham, A. Mills, J. Borghi, M. Koblinsky, D. Osrin. Maternal survival 5 - Maternal health in poor countries: the broader context and a call for action, Lancet, Vol. 368, No. 9546, 1535-1541, 2006

[6] C. AbouZahr. Global burden of maternal death and disability, Br Med Bull, Vol. 67, 1-11, 2003

[7] J. Scott. Rational Choice Theory. Understanding Contemporary Society: Theories of The Present, Sage Publications, USA, 2000.

[8] STATcompiler. MEASURE DHS. Calverton, MD: Macro International Inc, 2008

[9] M. L. Telfer, J. T. Rowley, E. L. Walvaren. Experience of mothers with antenatal, delivery and postpartum care in rura Gambia, Afr J Reprod Health. Vol. 6, No. 1, 74-83, 2002.

[10] Ghana Statistical Service (GSS), Ghana Health Service (GHS), ICF International. 2015. Ghana Demographic and Health Survey 2014, GSS, GHS, and ICF International, Rockville, Maryland, USA, 2015.

[11] $\mathrm{MOH}$. Guideline for implementing the exemption policy on maternal delivery, Ministry of Health, Accra, Ghana, 2005.

[12] G. Homans. Social Behaviour: Its Elementary Forms, Routledge and Kegan Paul, London, 1961.

[13] Ghana Statistical Service. 2010 Population and Housing Census. Summary Report, Ghana Statistical Service, Accra, 2010.

[14] J. W. Creswell. Research design: Qualitative, quantitative, and mixed methods approaches, SAGE Publications Incorporated, USA, 2009.

[15] A. M. L. Ntambue, K. F. Malonga, M. Dramaix-Wilmet, P. Donnen. Determinants of maternal health services utilization in urban settings of the Democratic Republic of Congo - a case study of Lubumbashi City. BMC Pregnancy and Childbirth, Vol. 12, No. 66, 1-12, 2012. Available at http://www.biomedcentral.com/1471-2393/12/66

[16] Kenya Demographic and Health Survey 2014: Key indicators. The DHS Program. Available at https://dhsprogram.com/pubs/pdf/fr308/fr308.pdf.

[17] S. K. Shrestha, B. Banu, K. Khanom, L. Ali, N. Thapa, B. Stray-Pedersen, B. Devkota. Changing trends on the place of delivery: why do Nepali women give birth at home? Reprod Health, Vol. 9, No. 25, 1-8. Available at http://www.reproductive-health-journal. com/content/9/1/25

[18] A. F. Ngowi, S. R. Kamazima, S. Kibusi, A. Gesase, T. Bali. Women's determinant factors for preferred place of delivery in Dodoma region Tanzania: a cross sectional study, Reproductive Health, Vol. 14, No. 112, 1 - 8, 2017.

[19] Y. A. K. Enuameh, S. Okawa, K. P. Asante, K. Kikuchi, E. Mahama, E. Ansah E, C. Tawiah, K. Adjei, A. Shibanuma, K. Nanishi, F. Yeji, E. O. Agyekum, J. Yasuoka, M. Gyapong, A. R. Oduro, G. Q. Asare, A. Hodgson, M. Jimba, S. Owusu-Agyei. Factors Influencing health facility delivery in Predominantly Rural communities across the three Ecological Zones in Ghana: a cross-sectional study. PLoSONE, Vol. 11, No.3, 1 - 16, 2016. Available at https://doi.org/10.1371/journal.pone.0152235

[20] B. Amooti-Kaguna, F. Nuawaha. Factors influencing choice of delivery sites in Rakai district of Uganda, Social Science \& Medicine, Vol. 50, 203-213, 2000.

[21] M. Mrisho, A. Joanna, S. Adiel, K. Mushi, B. Obrist, H. Mshinda, M. Tanner, D. Schellenberg. Factors affecting home delivery in rural Tanzania, Vol. 12, No. 7, 862-872, 2007.

[22] D. Maine, D. A. The Safe Motherhood Initiative: why has it stalled? Am J Public Health, Vol. 89. No. 4, 480-482, 1999.

[23] H. Mahler. The safe motherhood initiative: a call to action, Lancet, Vol. 1, No. 8534, 668-670, 1987.

[24] G. L. Darmstadt, Z. A. Bhutta, S. Cousens, T. Adam, N. Walker, L. de Bernis. Lancet Neonatal Survival Steering Team: Evidence-based, cost-effective interventions: how many newborn babies can we save? Lancet, Vol. 365, No. 9463, 977-988, 2005.

[25] K. A. Senah. A Presentation on Maternal Health delivered at Abokobi Women's Training Centre. Accra: Ghana, undated.

[26] C. R. Titaley, C. L. Hunter, M. J. Dibley, P. Heywood. Why do Some Women Still Prefer Traditional Birth Attendants and Home Delivery?: A Qualitative Study on Delivery Care Services in West Java Province, Indonesia, BMC Pregnancy and Childbirth, Vol. 10, No. 43, 2010.

[27] M. I. Nogueira. Assistência pré-natal: prática de saúde a serviço da vida, Hucitec, São Paulo, 1994.

[28] R. Jewkes, N. Abrahams, Z. Mvo. Why do nurses abuse patients? Reflections from South African obstetric services, Soc Sci Med, Vol. 47, 1781-95, 1998.

[29] S. C. L. Gabrysch, E. Bedriñana, M. A. Bautista, R. Malca, O. M. R. Campbella, J. J. Mirandaa. Cultural adaptation of birthing services in rural Ayacucho, Peru. Lessons from the field, Bull World Health Organ, Vol. 87, 724-729, 2009. 
[30] C. A. Iyaniwura, Q. Yussuf. Utilization of antenatal care and delivery services in Sagamu, south western Nigeria, Afr J Reprod Health, Vol.13, No. 3, 111-122, 2009.

[31] A. N. Bazzano, B. Kirkwood, C. Tawiah-Agyemang, S. Owusu-Agyei, P. Adongo. Social costs of skilled attendance at birth in rural Ghana, Int J Gynaecol Obstet, Vol. 102, 9194.

[32] N. Ishikawa, K. Simon, J. D. H. Porter. Factors affecting the choice of delivery site and incorporation of traditional birth customs in a refugee camp, Thailand International Journal of Gynecology and Obstetrics Vol. 78, 55-57, 2002.

[33] V. Perry. Witchcraft, Ghosts \& Spirits: Superstitions in West Africa, 2015. Online available at http://www.brighthubeducation.com/social-studies-help/12 4272-superstitions-from-west-africa/.
[34] M. Fischer. Childbearing in Ghana: How beliefs affect care. African Diaspora ISPs. Paper 76, 2002. Online Available at http://digitalcollections.sit.edu/african_diaspora_isp/76.

[35] J. Kitui, S. Lewis, G. Davey. Factors influencing place of delivery for women in Kenya: An analysis of the Kenya demographic and health survey, BMC Pregnancy and Childbirth Vol. 13, No 40, 1-10, 2013.

[36] H. E. Onah, L. C. Ikeako, G. C. Iloabachie. Factors associated with the use of maternity services in Enugu, southeastern Nigeria, Social Science \& Medicine, Vol. 63, No. 7, 1870-1878, 2006.

[37] S. Thaddeus, D. Maine. Too far to walk: maternal mortality in context, Social Science \& Medicine, Vol. 38, No. 8, 1091-1110, 1994. 